\title{
Stickiness in academic career (im)mobilities of STEM early career researchers: an insight from Greece
}

\author{
Charikleia Tzanakou ${ }^{1,2}$ (iD) \\ Published online: 1 October 2020 \\ (C) The Author(s) 2020
}

\begin{abstract}
Academic and policy discourse has idealised academic mobility despite studies showing that it can have adverse effects on individuals' experiences and contribute towards exacerbating existing inequalities. This article focuses on career (im)mobility stories of science, technology, engineering and mathematics (STEM) early career researchers that are variously sticky with emotion and affect. It places emphasis on the challenges, frictions and emotional tensions for early career researchers as part of this decision-making, irrespective of whether they decide to move or not. To do this, it deploys the concept of stickiness, which allows investigating the intersection and co-construction of embodied experiences of early career academics with the internationalisation discourse of academic excellence which are not often brought together. Focused on a largely under-examined population and context, it is based on a qualitative analysis of 15 in-depth interviews with a subsample of survey respondents, as part of a mixed methods study of Greek researchers in STEM. This article compares two groups of early career researchers who are seemingly at odds but have a lot in common: those with a highly international outlook moving to build an international profile and those who decide to stay and pursue research aspirations within a national context. Stickiness is demonstrated in two ways: stickiness to establishing an international profile and an academic career dictated by the internationalisation discourse; stickiness to affective considerations which are temporal, fluid and often understated. The main difference is how early career researchers address this stickiness: through the normative international mobility or participation in collaborative funding programmes. This article shows academic mobility is not only associated with benefits but can entail negative implications for individuals. It also provides empirical insights into hidden STEM early career researchers and elaborates a concept of stickiness in academic (im)mobility with discursive and affective layers, highlighting the importance of considering affect in career development scholarship.
\end{abstract}

Keywords Academic (im)mobility · STEM · Stickiness · Career gender · Early career researchers · Greece

Charikleia Tzanakou

ctzanakou@brookes.ac.uk

Extended author information available on the last page of the article 


\section{Introduction}

Academic and policy discourse has idealised academic mobility in two ways, through the ideal academic who is free $24 / 7$, unconstrained, unattached and flexible and through the idealisation of mobility as a significant and increasingly required part of international academic careers, knowledge production and innovation. For example, 'an academic is a free agent and can move his or her career and research agenda fairly easily from one university to another' (Baruch and Hall 2004, p.249). Mobility has often been investigated as a resource for career development of individuals (Tzanakou and Behle 2017; Murphy-Lejeune 2001; Crossman and Clarke 2010), establishing an international profile (Leemann et al. 2010; Morano-Foadi 2005) or contributing to national economic growth and advancement (brain-drain/brain-gain) (Gibson and McKenzie 2011).

While there is a wealth of studies on educational mobility, less attention is paid to the experiences of graduates and postgraduates (Rizvi 2010; Ackers and Gill 2009). As Bilecen (2013, p.669) emphasises:

postgraduate students are a very important subject of study because they are in a phase of transition from being consumers of education to producers who are appreciated for their academic achievement and innovation capabilities, which will have an influence of the reputation of the university and later of the country.

Moguérou (2006, p.2) underlines the importance of investigating the mobility of $\mathrm{PhD}$ candidates since they are highly mobile, facilitating beneficial synergies for the enhancement of scientific knowledge. Furthermore, they play a critical role in 'the conduct of research and innovation in national innovation systems' and their mobility can have far-reaching implications for economic growth of the home-host countries. Across disciplines, mobility is more of an urgent matter in regard to science and engineering $(\mathrm{S} \& \mathrm{E}) \mathrm{PhD}$ candidates who have been acknowledged globally as a key part of a dynamic economic strategy contributing to national competitiveness and knowledge-based economies (Freeman 2005). Compared with social scientists, mobility of natural scientists is more likely to be required for career progression (Herschberg et al. 2018). Furthermore, research on academic mobility highlights personal considerations but it only touches on the embodied experience of mobility of $\mathrm{PhD}$ candidates and early career researchers, specifically its 'social and affective dimensions' (Morley et al. 2018, p.551).

This article addresses this knowledge gap by examining the experiences of career mobility amongst $\mathrm{PhD}$ candidates in science, technology, engineering and mathematics (STEM) and in a relatively neglected national context, Greece. Two different groups of early career researchers are compared: those with a highly international outlook moving to build an international profile (who experience long-term mobility either for pursuing a $\mathrm{PhD}$ and/or a postdoc) and those who decide to stay and pursue their research career within a national context. This comparison shows that these groups have a lot in common in the experience of career (im)mobility.

This article considers doctoral mobility as a form of academic mobility. Thus the term of early career researchers is inclusive of $\mathrm{PhD}$ candidates who are contributing to knowledge production.

It focuses on international spatial long-term mobility (more than 3 months) which includes doctoral and postdoctoral mobility (the first 5-7 years after the $\mathrm{PhD}$ ) of Greek STEM early career researchers. Although a small country, Greece has an increasing number of $\mathrm{PhD}$ 
candidates with 7.3 doctorates per thousand economically active population, which places Greece in the 9th position out of 22 countries (EKT 2015). Greece demonstrated a high percentage of doctorate holders with international mobility (18.9\%), occupying the 5th place following Malta, Hungary, Spain and Portugal (EKT 2015). Recent data show that Greek doctorate holders not only moved more frequently but also stayed for longer periods abroad (ibid). The statistics are fascinating, but we know little about the stories and mobility decisions of Greek early career researchers. This article investigates how (im)mobility features in the decision-making and early career experiences of Greek STEM PhD graduates who have completed a PhD either in Greece and the UK. This article asks the questions: how do Greek researchers in STEM decide and experience (im)mobilities during their early career paths? What frictions, tensions and hidden challenges do they encounter?

This article does not romanticise mobility as an unconstrained flexible process that is determined by the choices of the individual but places emphasis on the challenges, frictions and emotional tensions for early career researchers as part of the decision-making, irrespective if they decide to move or not. To do this, it deploys the concept of stickiness, which has previously been associated with location (Ackers and Gill 2009). Stickiness in this study is extended by introducing discursive and affective layers of stickiness in relation to academic (im)mobility, in order to explain why individuals are moving and why they are locked into a specific place. It draws on Ahmed's (2004) notion of stickiness because it treats emotion not as a fixed property of the individual, but as something that moves between bodies, where it can sometimes stick. Stickiness in this article shows that academic career immobility is affectively sticky with emotions, triggering happiness when it allows individuals to fulfil aspirations and research goals, and frustration when it raises frictions and tensions between discursive career expectations and personal life preferences. This dynamic concept opens up opportunities to explore the intersection and co-construction of embodied experiences of early career academics with the internationalisation discourse of academic excellence which are not often brought together.

This article has a twofold contribution. First, it provides empirical insights into the 'hidden' career immobility stories of STEM early career researchers that are variously sticky with emotion and affect. It shows academic mobility is not only associated with benefits but can entail negative implications for individuals. It presents stories of those early career academics who experience satisfying academic and research careers irrespective of the decision of being mobile by exploring other strategies beyond international mobility. Second, this article elaborates a concept of stickiness in academic immobility with discursive and affective layers, highlighting the importance of considering affect in career development scholarship.

The structure of the paper is as follows. The next section reviews the existing literature on mobility of early career researchers and the theoretical concepts mobilised in this article. The methodology section provides an overview of the data collection and analysis. The findings section is structured around the comparison of two groups: those with a highly international outlook moving to build an international profile and those who decide to stay and pursue their research career within a national context. The paper concludes by outlining its contributions and potential avenues for future research.

\section{What is known and how academic mobility can be conceptualised}

The idealisation of mobility has been increasingly challenged (Fahey and Kenway 2010; Robertson 2010), especially in regard to its unproblematic image in relation to affective 
narratives (Morley et al. 2018; Henderson 2019). International academic mobility can be also problematic in terms of access, experience and its effects for individuals and beyond. Researchers have raised concerns about mobility as a mechanism for enhancing neoliberalism in academia (Bauder 2015), spatial inequalities (Brooks and Waters 2011), structured inequalities (Sang 2017; Leemann et al. 2010; Herschberg et al. 2018) and the hegemony of Western academia (van Oorschot 2014). For example, women are less likely to be mobile suggesting the persistence of gender roles and structured inequalities in institutional practices (Giorgi and Raffini 2015). Furthermore, early career researchers are more likely to be internationally mobile in an effort to establish their research profile (Auriol et al. 2013).

Mobility is experienced differently and it depends on the intersection between a person's gender, age, ethnicity, socioeconomic background and contextual factors such as disciplinary affiliation, opportunity structures and obstacles in the labour market, national research and innovation systems in sending and destination countries (Morley et al. 2018).

Studies on spatial international mobility for $\mathrm{PhD}$ candidates and graduates have shown advantages in terms of increased wages (Di Cintio and Grassi 2017), increased scientific productivity (Aksnes et al. 2013), skills (Bauder et al. 2017) and network development (Netz and Jaksztat 2017). However, it can also have negative implications in both professional terms (Cruz-Castro and Sanz-Menéndez 2010) and affective consequences for individuals (Morley et al. 2018). Immobility is often associated with academic inbreeding with negative connotations and effects for individuals, institutions and academic systems (Horta 2013; Inanc and Turner 2011). While international mobility has been celebrated as a mechanism for knowledge exchange and production, this article suggests that there are other mechanisms contributing towards this purpose and immobility should not be demonised.

\section{Mobility during early career paths includes doctoral mobility}

There is a growing but still limited body of literature devoted to doctoral mobility (Henderson 2019; Auriol et al. 2013; van Bouwel et al. 2011; Bilecen 2013). Prospective PhD candidates attribute increasing significance on the quality of research groups and supervisors in mobility decisions due to the nature of the doctoral degree and its effect on employment opportunities post-PhD both in the home and host country (Delicado 2010). Similarly, mobility of scientists and academics is determined 'apart from economic, personal, or political factors, science specific factors such as prestige, recognition, and credibility' (Mahroum 2002, p.17). Personal and family factors act more as preventing rather than driving mobility (Ackers and Gill 2009). However, less emphasis is given on the systemic factors that influence the mobility decisions of researchers (Constant and D'Agosto 2010). For example, Italian academics living abroad emphasise structural considerations such as the 'lack of research funds in Italy' and the limited availability of opportunities to fulfil rewarding careers in their field. These concerns were also echoed by Italian scientists in the UK (Morano-Foadi 2006) who appreciated the meritocratic procedures in the UK academic system, the good working conditions and the greater reputation of systems abroad compared with those in Italy. Italy and Spain share similarities with Greece regarding low spending on research and characteristics of the academic systems leading early career researchers to leave due to 'under-funding of science, bureaucratic career structures, and lack of openness and transparency in recruitment' (Millard 2005, p.352).

Despite the pervading higher education internationalisation discourse (Morley et al. 2018), Greece has a very small number of international students and staff accessing the Greek academic system. In combination with the low investment of the Greek state and businesses 
on research, Greece is considered sitting at the periphery of the global knowledge production system, mainly exporting students and graduates. Greek $\mathrm{PhD}$ candidates in STEM disciplines have been amongst the most mobile compared with their European counterparts pursuing doctoral training in an EU member state other than their own country (Moguérou and Di Pietrogiacomo 2008, p.77).

Research has not been amongst the priorities of the Greek state as reflected in the research expenditure (EKT 2018) by state and business funds, although this seems to be slowly improving. Notably, Greek researchers have been quite successful in securing European funding. European funding has been key for enhancing research activity in Greece and has benefited $\mathrm{PhD}$ candidates and early career researchers in Greek institutions since there are limited funding opportunities for doctoral 'stipends' and postdoctoral positions. During 20002010, an increasing number of $\mathrm{PhD}$ studentships in Greek institutions have been dependent on the availability of EU-funded programmes such as HERAKLITOS and PENED along with EU collaborative programmes under the European Framework programmes. However, there is limited research on the role and the impact of this EU funding on Greek researchers.

\section{Conceptualising stickiness in academic career (im)mobilities}

The concept of stickiness has been used in migration literature in relation to its temporal character, with Ackers and Gill (2009) stating that mobility tends to 'become more "sticky" over the life course' suggesting that individuals are less likely to pursue mobility at a later stage due to increased family and community commitments. They call for further research since "the concept of stickiness and the reasons why people become "locked into" spaces remains undeveloped' (ibid, p.14). This article elaborates on this concept of stickiness which associates mobility strongly with location and introduces a new concept with discursive and affective layers of stickiness in relation to academic mobility to explain why individuals are moving and why they are locked into spaces.

In this effort, I draw on Ahmed's work (2004) who intertwines bodily and discursive dimensions through sticky concepts and sticky affect as useful theoretical tools for exploring academic mobility (Morley et al. 2018) due to their dynamic character in capturing co-construction of embodied experiences and cultural-political discourses. Ahmed (2004) highlights the stickiness of objects leaving sticky impressions on bodies and demonstrates how such impressions are linked to the making of national discourses. While she does not refer explicitly to career mobility, she emphasises a dynamic and informative relationship between emotions, movement and attachment which is reflective of the embodied experience of movement. She notes how the idealisation of movement - in the context of queer theorycan become a way for exclusion, otherness and disadvantageous positioning for those who cannot move as freely.

Similarly, I use the concept of stickiness to show that academic career (im)mobility is affectively sticky with emotions, triggering happiness when it allows individuals to fulfil aspirations and research goals, and frustration when it raises frictions and tensions between discursive career expectations and personal life preferences. This dynamic concept allows me to show the intersection and co-construction of embodied experiences of early career academics with the internationalisation discourse of academic excellence which are not often brought together. Furthermore, the idealisation of academic mobility as an increasing requirement for international academic careers has led to exclusions of certain groups and binary distinctions between mobility and immobility, movers and stayers with the former always 
being portrayed in a more positive light than the latter. In an effort to examine academic (im)mobility coupled with the intention to highlight the tensions, frictions and affects entailed in academic career mobility, I use the concept of 'stickiness'. Careers are complex phenomena and there is a continuous debate with a plethora of theories competing to explain how careers are constructed (Bimrose et al. 2005). The systems theory framework addresses the continuous interaction between individual and contextual variables and seems to be most appropriate for understanding careers (for more see Patton and McMahon 1999). Similarly, migration theories have tried to explain migration on the basis of an interaction between individual and contextual considerations using the concept of embeddedness. King (2002, p.101) refers to 'double embeddedness of migration' distinguishing between individual and macro scales:

at the individual scale, migration must be embedded in a migrant's life course (and in some cases of the life-course of the family, even across generations); and at the macro scale, the study of migration must be embedded in societies and social processes of both the countries/places of origin and of destination

Findlay and Stockdale (2003) used social and temporal embeddedness of migration to show how individuals' decisions are socially embedded and determined by the economic and cultural environments in which they operate in. Embeddedness therefore is built on the assumption that individual lives and experiences reflect the wider sociocultural context and simultaneously sociocultural conditions affect perceptions, beliefs and identities and can become enablers and/or barriers for mobility and migration.

This article focuses on academic at early career stage where (im)mobility decisions have become an increasing consideration of academic careers. Concentrating on the interaction between lived experiences and discursive layers which are in alignment with individual and contextual considerations in the systems career theory and the embeddedness concepts presented above, it identifies two dimensions of stickiness in academic career (im)mobilities: the stickiness to discourses at disciplinary, institutional and the wider international higher education sphere and how at especially early career stage these influence academic career perceptions, decisions and attitudes and the stickiness to affective considerations (implied in the individual factors). In line with previous work (Morley et al. 2018), this article shows that these dimensions intersect and demonstrate how lived experiences challenge the discourse of higher education internationalisation with the idealised mobile subject which appears carefree, available 24/7 and unconstrained (Fabricius et al. 2017; Knights and Richards 2003; Leemann et al. 2010). Furthermore, this discourse suggests that the freedom to move will enable researchers to develop contacts and networks, contribute to knowledge exchange and production and establish an international profile that will facilitate their career progression. This all-pervading internationalisation discourse which operates in the background of the interviewees' decisions is discussed along with the intersecting discourses operating within the disciplines and institutions (often described as meso level). This is reflected through the two approaches that interviewees follow to comply with the internationalisation discourse: (a) through long-term geographical mobility and (b) through collaborative European programmes.

Compared with previous research focusing on migrant/mobile academics, the stickiness concept does not only apply to the latter but also on those who have remained in the same national sometimes even institutional context throughout their early academic career. 


\section{Methodology}

The data were drawn from a mixed methods study that investigated the early career paths of Greek $\mathrm{PhD}$ graduates in natural sciences and engineering who completed their $\mathrm{PhD}$ studies in UK and Greek universities between 2002 and 2008. A comprehensive database of this population was developed for the purposes of this study. Participants completed an online survey which focused on their $\mathrm{PhD}$ experience and transition to the labour market, from which 244 responses were received. It was challenging to identify Greek $\mathrm{PhD}$ graduates who completed their studies in the UK, and thus only 50 of these had been UK-educated. This article is based on 15 semi-structured interviews with $\mathrm{PhD}$ graduates identified through the online survey. The selection of doctoral graduates for the interviews was based on their willingness to be further contacted while they represented different early career experiences, for example, in terms of their educational background (a PhD in the UK or Greece), discipline (biology, computer/electrical engineering, physics), gender and country of employment (Greece or abroad) (see Table 1).

The interview guide consisted of a series of open thematic questions which allowed for further exploration of the experiences of doctoral education and the subsequent career path of $\mathrm{PhD}$ graduates including their (im)mobility experiences and decisions. It was informed by the survey responses and the curriculum vitae of interviewees which were provided in advance of the interview.

Telephone interviews lasted between 1 and 2 and were all audio recorded and transcribed. For this article, the focus was on the responses to questions about when they first considered pursuing a $\mathrm{PhD}$, where and why they pursued a $\mathrm{PhD}$ in the selected institution/research group, what alternatives they considered and, similarly, how and why they decided to undertake specific posts in their early career paths (what were their alternatives). An Excel file was developed with descriptive codes for each interviewee including characteristics (gender, age, partner/children) and educational background (discipline, institution, country of $\mathrm{PhD}$ ) as well as current employment (job title, organisation-sector, country) and mobility patterns.

Following this, two groups of early career researchers were compared who were seemingly at odds in academic studies: those with a highly international outlook moving to build an international profile and those who decide to stay and pursue research aspirations within a national context. Summaries for all interviewees were developed to understand their career journey and the factors and conditions surrounding their career and mobility decisions. While emotions and affect considerations in individuals' decisions and experiences of (im)mobility were a common overarching theme from the very beginning, the internationalisation discourse of excellence became evident when the comparison of the summaries showed that even those confined in the national context (initial theme was 'national careers') had an international profile, working in cross-national research projects and contributing to high-impact international publications. The subthemes of supervisors' role, gender and contextual considerations were also identified. The stories of the interviewees showed that these themes were intersecting and co-constructing academic (im)mobilities and this interaction demonstrated the challenges, frictions and tensions of academic mobility decisions and experiences. The stickiness concept was thus seen as an appropriate lens to capture these frictions and bring together the discursive and lived experience dimensions together.

In the second stage of analysis, the summaries were reread with a stickiness lens to understand the points of stickiness and the individuals' responses. This led to refining the 


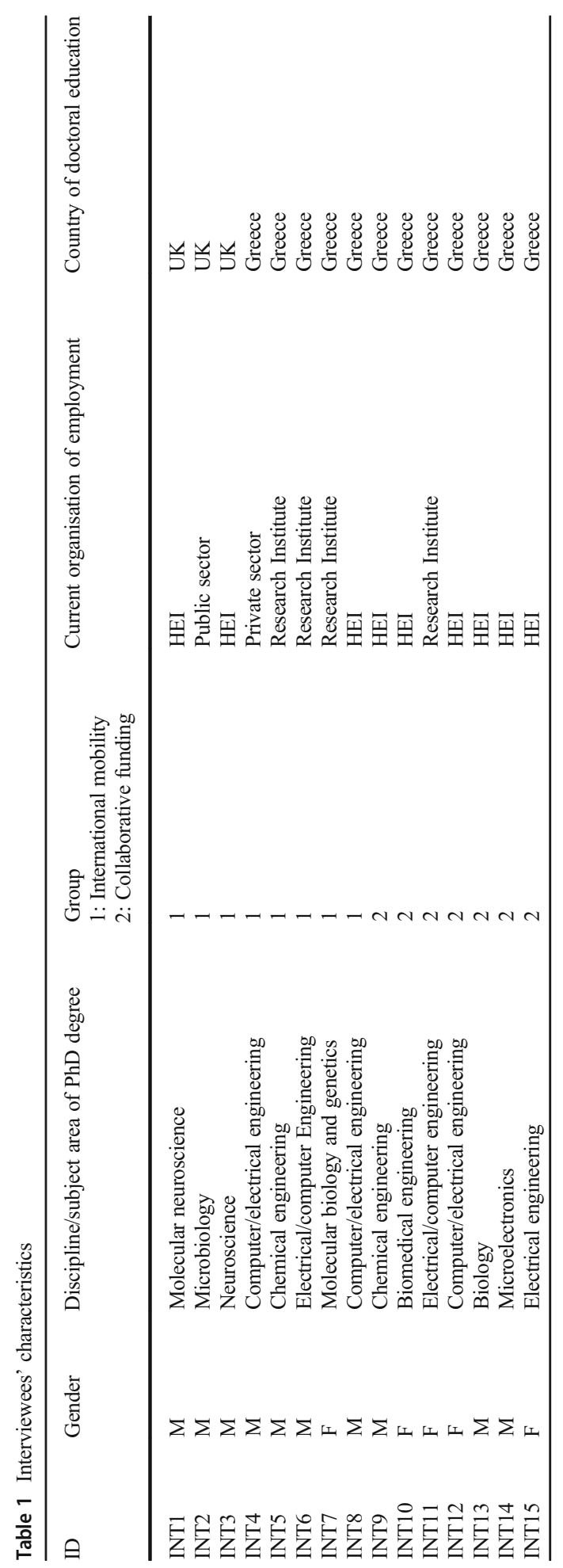


two overarching themes mentioned above but also led to two subthemes as responses to stickiness; 'international mobility' and 'collaborative funding'.

My positioning as a Greek researcher in the UK academia informed decisions around the purpose and the methodological design of this study. There was scarce information about how the early career paths of Greek researchers compared when they completed their doctoral education in Greece and the UK and this project aimed at providing an insight on how (im)mobilities could help careers. Conducting the interviews in Greek facilitated access and rapport with the interviewees who felt comfortable in sharing their stories. Due to my cultural background and familiarity with the local, sociocultural and political contexts (Tillman 2016) and meanings of language, I was able to develop a culturally nuanced approach (Chen and Bore 2010; Temple and Edwards 2002), as an 'indigenous insider' (Banks 2016; Pelzang and Hutchinson 2018).

Participants were well versed in academic research and due to no previous research having targeted them as a group, they seemed happy to contribute to this knowledge gap. A few participants commented upon the formality of the request (some received a formal letter from their Alumni offices) from a prestigious UK university, in particular from a $\mathrm{PhD}$ candidate with a Greek name. In one respect, I may have been understood as an indigenous outsider with a privileged $\mathrm{PhD}$ studentship in the UK. I was seen as belonging to the wider group being studied. As a $\mathrm{PhD}$ candidate myself, although not in STEM, this benefited me in generating accurate data. Being an outsider to the Greek academic system helped me to ask questions that 'insiders' might take for granted (e.g. how the Greek academic system works in terms of career progression) and trigger their reflective thoughts (e.g. asking for their views on statement about comparison of academics with international mobility and without). Understanding the local context and language but not being part of it (Subedi 2006), enabled reflecting on the data collected and enhanced the cultural integrity of the study (Pelzang and Hutchinson 2018; Merton 1972).

\section{Findings}

In this section, two groups of early career researchers are compared who are seemingly at odds in academic studies: those with a highly international outlook moving to build an international profile and those who decide to stay and pursue research aspirations within a national context. This comparison shows that these groups have a lot in common, with stickiness demonstrated in two ways affecting each other: stickiness to the aspiration of establishing an international profile and an academic career that fulfils their research goals dictated by the internationalisation discourse and stickiness to affective considerations which are temporal, fluid and often understated. The main difference between these groups is how they address this stickiness to fulfil their career goals: one through the normative international mobility and the other through participation in collaborative (often EU) programmes. The findings are presented through a comparison of these groups rather as the two aspects of stickiness with a view to illustrate how it operates in both layers simultaneously (internationalisation discourse and affect) and how the latter intermingle and influence career decisions.

\section{Stickiness and international mobility}

For early career academics, international mobility is stickier compared with subsequent career stages since it can help researchers to establish their research profile. But are they autonomous and free to move anywhere they like? In this study, researchers were passionate in 
developing further their research agenda. Completing a $\mathrm{PhD}$ reinforced the desire for research and knowledge becoming their 'career mission', affecting career and (im)mobility decisions. Eight interviewees fell within this group comprising one woman and seven men. The $\mathrm{PhD}$ and often the postdoc supervisors in this group played a vital role in the career choices and paths of the interviewees through providing advice, using their professional contacts and networks to help them pursue mobility. Funding, reputation, supervisor and $\mathrm{PhD}$ topic were the main reasons behind the choice of institution for doctoral studies. They all had international work experience in academic and research institutions abroad and followed seemingly linear career paths with completing all their higher education studies consecutively. Two cases in this group (INT2, INT4) were not working in HEIs but they performed similar tasks to researchers in non-academic settings. In this group, early career paths were comprised of fixed-term contracts of 2-3 years and there was high institutional and geographical mobility between career posts. The majority of these cases were satisfied in their current employment roles as they loved going to work, learning new things, undertaking challenging tasks and being independent.

This group abided to the internationalisation discourse with mobility as a prerequisite for excellence and knowledge exchange/production and career (Jepsen et al. 2014; Leemann et al. 2010). Geographical mobility was used to fulfil the stickiness of mobility decisions on somewhat predetermined opportunities and locations (often in the Global North) with the 'best' labs, professors and research groups to further their research agenda.

For example, INT2 finished a PhD in biological sciences in a London-based university and described how his $\mathrm{PhD}$ led him to a sticky career conformed to the internationalisation discourse that which requires mobility for career development:

There are positive and negative consequences derived from the $\mathrm{PhD}$ because you invest half of your life - because it is certain that it will take you time - and then it is also a career mission. It is not often that you will do a $\mathrm{PhD}$ and then you will start working on something irrelevant for example in a bank (INT2)

He completed a postdoc in the same institution where he did his $\mathrm{PhD}$ and then accepted another postdoc in the US which was the 'next logical step':

It was the natural progression. When I started my $\mathrm{PhD}$, my supervisor had told me 'at some point you would have to go to US if you want to follow the path you are interested in'. We have a nickname for this, we call it BTA = Been To America, something like a qualification. You have to do it otherwise there is no great career progression. Therefore, I knew that at some point I would have to do this. In one way or another I knew that I would return to UK finally. (INT2)

The stickiness of careers in the intersecting discourse of internationalisation and academic discipline was reiterated in his story, where it was required to have a US experience in his field because the research processes in the US were very different than in Europe. Soon after this, he moved to a permanent post in the UK where he conducted research closely aligned to his $\mathrm{PhD}$ (his $\mathrm{PhD}$ and US experience were required for this move). He did not consider staying in the US, which functioned as stepping stone for better career progression: 
it is a common secret, you go and see how the system works but you do not stay there. (INT2)

Career and mobility decisions were also sticky to affect since they involved working at an isolated US rural town which was 'boring' and felt like 'survival exercise', due to the conservative mentality and isolation during wintertime. Location and lifestyle were significant parameters, but his research agenda could not be accommodated in big cities since all research centres were built in isolated areas due to the nature of his subject area. Thus, while stickiness to the intersecting internationalisation and disciplinary discourse necessitated moving to a limited number of destinations, suggesting how mobility for the idealised academic subject can still be constrained discursively, there were subsequent affective issues such as feeling isolated and/or lonely away from home and personal relationships.

Similarly, INT6, a Greek-educated PhD graduate, moved to Switzerland with a prestigious fellowship to advance his $\mathrm{PhD}$ research and then was about to move to Germany for a postdoc with prospects for a permanent academic post. His mobility decision was further contextualised comparing opportunities and wider environment within the destination and the home country (Greece) such as the prospect of a permanent post along with a lab where he could meet his research goals and escape the financial crisis in Greece. When asked about the effect of the $\mathrm{PhD}$, he corroborated the stickiness of academic career which 'obliges you' to live away from home, without knowing where it will lead you next:

Of course the $\mathrm{PhD}$ affects (your life) because you are obliged to live away from your home.[..] and since you do not have many employment options, you need to leave from Switzerland for Germany and then I don't know where, this affects your personal life because you know that if you don't have a base and prospects for some years, it is very difficult to make a family.. [..] you weigh things and you say, do I want to get married and make a family now..to stay there or do I want to delay it a bit

Similarly, he raised the affective considerations that show the tension between the expectations of an international research career following research passion and a personal life which required stability - sticking to a base in order to find a partner and make a family. Thus, while he enjoyed his research and recognition from the international community, he was also worried about how his research pursuit has and will affect his personal life. This account shows the temporality of mobility decisions affected by future life goals (Netz and Jackstat 2017). It suggests stickiness being linked to life course inflexibility where career paths seem to be directed by an intersection of strong academic career orientation, an internationalisation discourse that obliges individuals to be mobile to such an orientation, and affective considerations about partnerships and family.

Contrary to the idealisation of mobility, interviewees reported how their decisions resulted from an interaction of personal issues/preferences and structural conditions highlighting the embeddedness of (im)mobilities. The specialised knowledge acquired through the $\mathrm{PhD}$, coupled with the need to pursue further their research agenda and establish an international research profile, was characterised by stickiness of academic mobility decisions being 'dictated' by internationalisation and disciplinary discourses. These stories show how 'scientific clusters' (Millard 2005; Gill 2005) and excellent research centres are driving careers and mobility decisions through the discourse of internationalisation of excellence (Herschberg et al. 2018) where particular types of international mobility are valued and recognised for career development located in the Global North, reflecting postcolonial patterns (ibid; Altbach 2004; Enders and Musselin 2008). 
Prestigious scientific clusters such as those in the US seemed to be more of a temporary stepping stone for career progression, a mobility intermediate station. While they were all attracted by the research conditions offered enabling them to pursue their research agenda, there was also an affective layer which made them move again such as location (as in its surroundings, characterised as flat or isolated), the lifestyle (good quality of life) and/or being close to family.

The aforementioned accounts suggest how academic (im)mobilities can be sticky to life course inflexibility demonstrating how academic careers can be predetermined. Ackers and Gill (2009, p.16) report that scientists are more likely to be immobile over the life course ('mobility to become more sticky over the life course') due to establishing partnerships and families while early stage researchers are not affected by concerns around family as much. Beyond their interpretation of stickiness as immobility, stickiness in these accounts shows the intersecting discursive and affective layers where early career researchers have increasing pressures compared with more senior researchers to establish an international research profile along with affective considerations that include family concerns in some cases.

\section{Stickiness and collaborative funding programmes}

Similarly to the internationally mobile interviewees, this group's career decisions were also defined by their $\mathrm{PhD}$ research, the conditions surrounding doctoral and postdoctoral research in Greece and the aspiration to undertake academic/research employment. There were seven interviewees in this group: four women and three men.

All interviewees in this group had completed their doctoral training (and often all their studies) in Greek institutions and they had not moved apart from short stays beyond Greece. Although they considered mobility abroad during and after their doctoral education, they had stayed in Greece due to favourable conditions fulfilling not only study/ career aspirations but also affective needs. Being able to remain near to friends and family deterred them from going abroad. Collaborative funding mainly European linked to supervisors' projects during and after their $\mathrm{PhD}$ played a key role in remaining in Greece and was a strategy to establish an international profile aligned with the internationalisation discourse without having to move.

The European funding availability in an underfunded research environment in Greece enabled the interviewees to stay and access relevant paid roles during the $\mathrm{PhD}$ and postdoc albeit often insecure in terms of short, fixed-term contractual arrangements. This funding also enabled developing international contacts and networks which are key at early career stage, through participating in Consortia projects:

EU programmes helped a lot, people got paid, thus there was an incentive to stay here and despite the difficulties and the lack of organisation and infrastructure - there is no comparison between the institutions abroad - there were incentives to stay and make an effort. Therefore, there was a new framework that gave birth to many doctoral candidates and graduates subsequently, at least in how I have lived this situation at my institution. (INT11)

While staying in Greece for doctoral studies facilitated building professional and academic networks in the national academic labour market, completing a $\mathrm{PhD}$ in a prestigious university 
might also be advantageous (Karamessini 2004). Nevertheless, this seems to have changed with the expansion of Greek higher education, the establishment of postgraduate degrees and the high production of domestically educated $\mathrm{PhD}$ graduates. The previous interviewee described how the domestic postgraduate education system has improved affecting the internationalisation and institutional discourse about mobility:

We are able now to compete with those who went abroad, although we stayed here (in Greece) and we did not go for a postdoc abroad. We have equally good publications in good journals. In the past, we might not have been able to compete, but not anymore [...] In the past, we would see people coming from very reputable US universities with awe. Because they did better quality research than we did. This might still be the case but we are definitely in a better position. (INT11)

Studies have shown the diffusion of the internationalisation discourse into institutional (meso level) discourses and policies making international mobility as a criterion for recruitment in STEM tenure track careers (Herschberg et al. 2018). In this group, the stickiness to the internationalisation discourse was reflected in their approach to engage with funding programmes which enabled research excellence, international networking and collaboration. Simultaneously, their careers complied with the internal academic labour market and the dominant institutional discourse of limited mobility. This was highlighted by an early career researcher who stayed in the same lab undertaking a postdoc, working in the collaborative programmes of his supervisor. He emphasised a lacking 'mobility mentality' which was reflected in the informality of recruiting postdocs:

most of the decisions (for postdocs) are taken through discussions, there is not a mentality for mobility, to look for something better. Until recently, I didn't have to do a CV. When you get a job, you stay. (INT9)

Similarly to the previous group, the $\mathrm{PhD}$ supervisor role was key to getting postdoctoral positions soon after their PhD. However, these posts were located in the same lab or research group rather than at another institution within or beyond Greece. This was also reported by a woman interviewee who completed all her studies in the same institution. She highlighted the importance of previous experience working in the same group/lab as part of her $\mathrm{PhD}$ in getting subsequent posts, because 'each one keeps their collaborators more or less' (INT12). When asked why she decided to take this postdoctoral job, she confirmed this mentality, the effect of familiarity and not having to start again:

I knew the environment, I did not have to prove again, I had strived to set up some things for example in terms of respect, dignity, financial earnings, what tasks I will undertake.. [...] I like this city, [...] this job fulfilled me. And it is a nice job (INT12)

She also described her affective reluctance towards long-term mobility and stay away from family and beloved ones:

I like the idea of going on a trip, stay for a week-two and experience the culture if I can, but it seems tough to move somewhere, meaning I am terrified in a sense, for example loneliness in the beginning and having to set up my life somewhere else, requires guts and I don't think I have them (INT12) 
Similarly to the previous group, these posts were perceived 'as a natural progression' by the interviewees and they were linked to specific research projects under fixed-term contracts which enabled the interviewees to build up their CV and increase the likelihood of being selected for a more permanent post. Of course, these entailed precarious contractual arrangements which are inherent to an underfunded research system along with sparse academic posts (which require ministerial approval).

This immobility mentality seemed to be further layered within gender and affect. In this group, mobility and career decisions were primarily interlinked with affective considerations. All the women in this group continued working in the same unit where they were awarded the $\mathrm{PhD}$. After 7-8 years on average from the $\mathrm{PhD}$ completion, they got open-ended contracts. Institutional and inter-institutional (im)mobility seemed to be gendered. The men participants, while they followed similar paths with initial fixed-term contracts in the same institution, had moved to other HEIs getting permanent posts, often much earlier compared with their women counterparts. Women academics were more likely to report being constrained in one location due to partners' considerations, family support and childcare received from grandparents. For example, one interviewee (INT11) stayed in the same Greek institution where she completed her PhD despite offers from the US for her and her partner. Remaining in the same institution was a result of various challenges entailed in inter-institutional and international mobility, although the latter were recognised as important for career progression. While moving to another institution in Athens entailed structural difficulties such as limited number of vacancies and enormous competition, inter-institutional mobility beyond Athens and international mobility meant choosing between paying for daycare or childcare by grandparents who provided a supportive environment for her family. Moving meant that she would have no access to this support.

While affective considerations played a key role in the choice and decisions about international mobility and early career paths of these interviewees, this choice might have been limited if they were not for the collaborative funding programmes which enabled them to remain in their country and undertake research that met their career and research goals. The interaction between contextual and individual considerations is also evident in this group through their examples of stickiness.

Those who remained in Greece through their studies and academic work experience experienced stickiness to the internationalisation discourse facilitated by the existence of European programmes which enabled collaboration and high-quality research. In this way, they contributed to international knowledge production even if they were only occasionally 'moving' for very short stays. These collaborations also had the potential to become opportunities where individuals carried on long-term and consecutive projects with partners in different countries and produce high-impact publications. Apart from financially supporting themselves during their early career path, this funding was beneficial in developing international networks and project management skills including budget allocation and time management.

In the idealised academia of internationally mobile-free bodies, the interviewees in this group are seen to be constrained in a national academic labour market, with adverse conditions in terms of research infrastructure and resources, slow career progression and lack of more secure academic posts. While Greece has limitations in terms of research expenditure and infrastructure with implications for researchers' careers, those who remained in research posts after their $\mathrm{PhD}$ presented a good research profile and contributed towards international knowledge production through collaborative funding programmes. Furthermore, this group enjoyed their everyday work and their research and were more likely to report negative emotions and affections in relation to mobility abroad rather than their immobility experience. 
Some of these stories could be described as academic inbreeding which is often linked to immobility with negative outcomes for individuals, institutions and academic systems (Horta 2013; Inanc and Turner 2011). However, there can be positive outcomes through the involvement in European collaborative projects which require occasional travel (or virtual presence) for short-term project meetings rather than moving one's life with them.

\section{Conclusion}

The ideal image of the free, unconstrained academic who is able to move globally to build an international research profile and contribute to knowledge production and innovation is still with us but far from true. This article contributes to the body of literature challenging this idealised image providing evidence from an under-researched geographical focus, often examined as an exporting context of highly skilled workforce (Labrianidis 2011). This article compares not only Greek STEM researchers who are internationally mobile but also those who remained in Greece for their education and their early career despite offers to move abroad. It shows that this idealised autonomy and freedom of choice is constrained in both groups albeit in different ways leading to different approaches to fulfil international academic careers.

The stickiness concept highlights the similarities between these two groups who seem at odds and demonstrates the continuously negotiable relationship between individual and contextual considerations. This is illustrated through the dynamic relationship between stickiness to intersecting discourses and affective considerations in academic (im)mobilities of STEM early career researchers leading to different approaches in fulfilling their career aspirations. Unsurprisingly, one group used the normative international mobility to establish the discursively required international profile which was somewhat predetermined spatially by international and disciplinary discourse of scientific excellence and temporally by affective considerations. Conversely, those who remained in Greece engaged in collaborativeespecially European programmes to establish a career profile in compliance with the international but also institutional/disciplinary mentality of the surrounding environment. This reinforced the stickiness of their careers to their affective considerations. The concept of stickiness enables the tensions and frictions between discursive and bodily dimensions to be documented to critique the idealised norm of academic mobility as equally accessible and beneficial to all. More studies need to provide stories and narratives of individuals to demonstrate the hidden tensions and frictions of academic mobility but also alternative strategies to mobility which can lead to academic excellence, career progression and affective fulfilment.

This study contributes to the limited body of literature on Greek early career STEM researchers and highlights both the structural limitations of the Greek research and innovation system and the benefits of EU funding as an alternative to mobility. Apart from being a source to support themselves, EU funding facilitated developing project management skills and the development of international contacts/networks with academics and professionals. This professional experience was helpful for their $\mathrm{CV}$, as well as for cementing their position in the research lab or team, as evidenced in their retrospective accounts. Thus, it was unsurprising to find that many Greek-educated participants in this study who had worked in European projects during their doctoral studies had a smooth transition to postdoc/research posts albeit on fixed term contracts and followed academic paths often within the same institutions where they completed their doctorates. This article does not suggest that these experiences were unproblematic and positive. All participants raised challenges staying in Greek academia but they 
were satisfied about the funding especially during the economic crisis to enable them to conduct research in an environment that met their professional goals and helped them juggle personal and affective considerations.

This article also shows how mobility is temporally and spatially more gendered. Considering that mobility is increasingly required for career development in STEM, it contributes towards the literature about the under-representation of women in STEM (European Commission 2019). In this study, women demonstrated less mobility than men not only in international moves but also inter-institutionally within Greece. Only one woman in this study moved internationally to establish her research profile while many women remained at the same institution (in Greece) where they completed their $\mathrm{PhD}$ and had developed an established network of contacts. Gender issues were not explicitly reported on internationally mobile interviewees, reflecting how affective and caring considerations might be silenced and/or hidden through the idealised image of a highly mobile, internationally established researcher. It also corroborates the idea that the slow progress of women in senior academic positions can be due to the encouragement and idealisation of mobility as a prerequisite for internationally successful careers, creating an impediment for both women and individuals with care considerations. These accounts provide suggestions about the stickiness of academic (im)mobilities to life course inflexibility which fall outside the scope of this article but open avenues to explore this in further research.

Being an academic has changed rapidly throughout the years with its increasing professionalisation and growing requirements. Access to $\mathrm{PhD}$ as an entry to academia might have expanded but remaining in the academia has been more challenging than ever. The idealised discourse of academics and academic mobility needs to be pragmatically reconsidered and stakeholders and institutions (academic communities, higher education institutions, funding bodies, governments and supranational bodies) should contribute to a new academic image that will be inclusive, realistic and careful in attending to the needs of individuals and societies.

Acknowledgments The author would like to thank: Emily Henderson and Nick Rumens for their supportive comments; and the two reviewers for their constructive criticism which helped refining this paper.

Open Access This article is licensed under a Creative Commons Attribution 4.0 International License, which permits use, sharing, adaptation, distribution and reproduction in any medium or format, as long as you give appropriate credit to the original author(s) and the source, provide a link to the Creative Commons licence, and indicate if changes were made. The images or other third party material in this article are included in the article's Creative Commons licence, unless indicated otherwise in a credit line to the material. If material is not included in the article's Creative Commons licence and your intended use is not permitted by statutory regulation or exceeds the permitted use, you will need to obtain permission directly from the copyright holder. To view a copy of this licence, visit http://creativecommons.org/licenses/by/4.0/.

\section{References}

Ackers, L. (2005). Scientific migration within the EU. Innovation: The European Journal of Social Science Research, 18(3), 275-276.

Ackers, L., \& Gill, B. (2009). Moving people and knowledge:scientific mobility in an enlarging European Union. Edward Elgar Publishing.

Ahmed, S. (2004). The cultural politics of emotion. Routledge.

Aksnes D.W., K. Rorstad, F. N. Piro, G. Sivertsen (2013) Are mobile researchers more productive and cited than non-mobile researchers? A large-scale study of Norwegian scientists. Research Evaluation 22(4), 215-223

Altbach, P. G. (2004). Globalisation and the university: myths and realities in an unequal world. Tertiary Education \& Management, 10(1), 3-25. 
Auriol, L., Misu, M., \& Freeman, R. A. (2013). Careers of doctorate holders: analysis of labour market and mobility indicators. In OECD Science, Technology and Industry Working Papers, 2013/04. OECD: Publishing. https://doi.org/10.1787/5k43nxgs289w-en.

Banks, J. A. (2016). The Lives and Values of Researchers: Implications for Educating Citizens in a Multicultural Society. Educational Researcher 27(7), 4-17.

Baruch, Y., \& Hall, D. T. (2004). The academic career: a model for future careers in other sectors? Journal of Vocational Behaviour, 64, 241-262.

Bauder, H. (2015). The international mobility of academics: a labour market perspective. International Migration, 53(1), 83-96.

Bauder, H., Hannan, C-A., Lujan, O. (2017). International Experience in the Academic Field: Knowledge Production, Symbolic Capital, and Mobility Fetishism. Population, Space and Place 23(6), e2040.

Bilecen, B. (2013). Negotiating differences: cosmopolitan experiences of international doctoral students. Compare: A Journal of Comparative and International Education, 43(5), 667-688.

Bimrose, J., Barnes, S. A., \& Brown, J. (2005). A systematic literature review of research into career-related interventions for higher education. Manchester: HECSU.

Brooks, R., \& Waters, J. (2011). Student mobilities, migration and the internationalization of higher education. London: Palgrave.

Chen, H-Y., Boore, J. R. P. (2010). Translation and back-translation in qualitative nursing research: methodological review. Journal of Clinical Nursing 19(1-2), 234-239.

Constant, A. F., \& D'Agosto, E. (2010). Where do the brainy Italians go?. In The labour market impact of the EU enlargement (pp. 247-271). Physica-Verlag HD.

Crossman, J. E., \& Clarke, M. (2010). International experience and graduate employability: stakeholder perceptions on the connection. Higher Education, 59(5), 599-613.

Cruz-Castro, L., \& Sanz-Menéndez, L. (2010). Mobility versus job stability: assessing tenure and productivity outcomes. Research Policy, 39(1), 27-38.

Delicado, A. (2010). Going abroad to do science: mobility trends and motivations of Portuguese researchers. Science \& Technology Studies.

Di Cintio, M., \& Grassi, E. (2017). International mobility and wages: an analysis of Italian PhD graduates. Ann Reg Sci, 59, 759-791.

EKT. (2015). Careers and mobility of doctorate holders in Greece - Edition 2015. Athens: National Documentation Centre.

EKT. (2018). Research and development expenditure and personnel in Greece in 2017 - main indicators. Athens: National Documentation Centre.

Enders, J. \& Musselin, C. (2008). Back to the future? The academic professions in the 21st century. OECD, Higher Education to 2030, Volume 1, Demography, OECD Publishing.

European Commission. (2019). SHE Figures 2018. Luxembourg: Publications Office of the European Union.

Fabricius, A. H., Mortensen, J., \& Haberland, H. (2017). The lure of internationalization: paradoxical discourses of transnational student mobility, linguistic diversity and cross-cultural exchange. Higher Education, 73(4), $577-595$.

Fahey, J., \& Kenway, J. (2010). International academic mobility: problematic and possible paradigms. Discourse: Studies in the cultural politics of education, 31(5), 563-575.

Findlay, A. M., \& Stockdale, A. (2003). The temporal and social embeddedness of migration: a methodological exploration using biographical analysis. In Geography Research Forum (pp. 4-29). Ben-Gurion University of the Negev Press.

Freeman, R. B. (2005). Does globalization of the scientific/engineering workforce threaten US economic leadership? NBER WP no. 11457, (July).

Gibson J. and D. McKenzie (2011). "Eight questions about brain drain," CReAM Discussion Paper Series 1111, Centre for Research and Analysis of Migration (CReAM), Department of Economics, University College London.

Gill, B. (2005). Homeward bound? Innovation: The European Journal of Social Science Research, 18(3), 319341.

Giorgi, A., \& Raffini, L. (2015, December). Love and Ryanair: academic researchers' mobility. In Forum Sociológico. Série II (No. 27, pp. 43-52). CESNOVA.

Henderson, E. F. (2019). A PhD in motion: advancing a critical academic mobilities approach (CAMA) to researching short-term mobility schemes for doctoral students. Teaching in Higher Education, 24(5), 678693.

Herschberg, C., Benschop, Y., \& van den Brink, M. (2018). Selecting early-career researchers: the influence of discourses of internationalisation and excellence on formal and applied selection criteria in academia. Higher Education, 76(5), 807-825.

Horta, H. (2013) Deepening our understanding of academic inbreeding effects on research information exchange and scientific output: new insights for academic based research. Higher Education 65(4), 487-510. 
Inanc, O., \& Turner, O. (2011). The effect of academic inbreeding on scientific effectiveness. Scientometrics, 88, 885-898.

Jepsen, D. M., Sun, J. J.-M., Budhwar, P. S., et al. (2014). International academic careers: personal reflections. The International Journal of Human Resource Management, 25(10), 1309-1326.

Karamessini M. (2004) Women's representation and progression in science careers in Greece, Research Reports No. 19, Centre for the Study of Law and Policy in Europe, University of Leeds.

King, R. (2002). Towards a new map of European migration. International journal of population geography, $8(2), 89-106$.

Knights, D., \& Richards, W. (2003). Sex discrimination in UK academia. Gender, Work \& Organization, 10(2), 213-238.

Labrianidis, L. (2011). Investing in drain. Athens: Kritiki publishers.

Leemann, R. J., Dubach, P., \& Boes, S. (2010). The leaky pipeline in the Swiss University system: identifying gender barriers in postgraduate education and networks using longitudinal data. Swiss Journal of Sociology, 36(2), 323.

Mahroum, S. (2002). The International Mobility of Academics: The UK Case (Universal Publishers, 2002).

Merton R. K. (1972) Insiders and Outsiders: A Chapter in the Sociology of Knowledge. American Journal of Sociology, 78(1), 9-47.

Millard, D. (2005). The impact of clustering on scientific mobility. Innovation: The European Journal of Social Sciences, 18(3), 343-359.

Moguérou, P. (2006) The brain drain of PhDs from Europe to the United States: what we know and what we would like to know. EUI Working Paper RSCAS no.2006/11

Moguérou, P., \& Di Pietrogiacomo, M. P. (2008). Stock, career and mobility of researchers in the EU. JCR Scientific and Technical reports. European Commission. Available at: http://erawatch.jrc.ec.europa. eu/erawatch/opencms/information/reports/countries/eu/report_mig_0011

Morano-Foadi, S. (2005). Scientific mobility, career progression, and excellence in the European research area. International Migration, 43(5), 133-162.

Morano-Foadi, S. (2006). Key issues and causes of the Italian brain drain. Innovation,19 (2): 209-20

Morley, L., Alexiadou, N., Garaz, S., González-Monteagudo, J., \& Taba, M. (2018). Internationalisation and migrant academics: the hidden narratives of mobility. Higher Education, 76(3), 537-554.

Murphy-Lejeune, E. (2001). Student mobility and narrative in Europe. The New Strangers. In Routledge Studies in Anthropology. London: Routledge.

Netz, N., Jaksztat, S. (2017) Explaining Scientists' Plans for International Mobility from a Life Course Perspective. Research in Higher Education 58(5), 497-519.

Patton, W. \& McMahon, M. (1999). Career development and systems theory: a new relationship

Pelzang, R., Hutchinson, A. M. (2018). Establishing Cultural Integrity in Qualitative Research. International Journal of Qualitative Methods 17(1), 160940691774970.

Rizvi, F. (2010). International students and doctoral studies in transnational spaces. In M. Walker \& P. Thomson (Eds.), The Routledge doctoral supervisor's companion: Supporting effective research in education and the social sciences (pp. 158-170). London: Routledge.

Robertson, S. L. (2010). Critical response to special section: international academic mobility. Discourse: Studies in the cultural politics of education, 31(5), 641-647.

Sang, K. (2017). Disability and academic careers. Retrieved October 18, 2017 from https://migrantacademics. files.wordpress.com/2017/05/disability-sang-may-2017.pdf

Subedi, B. (2006). Theorizing a 'halfie' researcher's identity in transnational fieldwork. International Journal of Qualitative Studies in Education 19(5), 573-593.

Temple, B., Edwards, R. (2016). Interpreters/Translators and Cross-Language Research: Reflexivity and Border Crossings. International Journal of Qualitative Methods 1(2), 1-12

Tillman, L. C. (2016). Culturally Sensitive Research Approaches: An African-American Perspective. Educational Researcher 31(9), 3-12.

Tzanakou, C., \& Behle, H. (2017). The intra-European transferability of graduates' skills gained in the UK. Journal of Ethnic and Migration Studies, 43(8), 1379-1397.

Van Bouwel, L. ,Lykogianni E. and Veugelers, R., (2011) Mobility Decisions of European Doctoral Researchers. Available at SSRN: https://ssrn.com/abstract=2105554

van Oorschot, I. (2014). Negotiating knowledges abroad: non-Western students and the global mobility of knowledge. Compare: A Journal of Comparative and International Education, 44(6), 895-915.

Publisher's note Springer Nature remains neutral with regard to jurisdictional claims in published maps and institutional affiliations. 


\section{Affiliations}

\section{Charikleia Tzanakou $^{1,2}$}

1 Centre for Diversity Policy Research and Practice, Oxford Brookes University, Oxford, UK

2 University of Warwick, Coventry, UK 